\title{
INFUSION PORTABLE SYSTEM
}

\section{Nasonov K., Pomazkov M., Kushnarev V., Yatsenko A.} sia

Amur State University, Blagoveshchensk, Russia, Amur State Medical Academy, Blagoveshchensk, Rus-

Abstract IPS is a device for infusion therapy in extreme conditions. The device is capable of infusion therapy in different mods. IPS has unique qualities for this device group.

Introduction. Modern infusion systems designed to assist patients in the comfortable conditions of hospital or home treatment. Traditional and modern mechanized, high-precision, expensive and heavy infusion systems used in hospitals do not have the mobility and are non-wearable. In addition to mobility, there is a need to provide a therapeutic effect infusion in extreme conditions. Extreme conditions are the eliminations of consequences of emergency situations, or aiding by military doctors on a battlefield and other situations. of IPS:

Materials and Methods After research the needs of special medical units, we have developed principles

1) Capacity infusion solution with protection against mechanical damage

2) Lack of specific consumable materials. This makes it possible to integrate our device in existing medicine standards

3) The ability to extend the functionality of the add-on modules

4) Reuse System

5) The lack of strict orientation in space

6) A lightweight construction

7) Wearable system

According to these principles have been developed and constructed a device for infusion therapy.

Results After researching the needs of specialized medical departments have been developed IPS principles. In accordance with the principles of IPS it was designed and constructed a device for infusion therapy in extreme conditions. Now the device is held pre-clinical trials.

Discussion and Conclusions At this stage, IPS successfully realizes the basic functions. The totality of these properties does not have any one device on the market of infusion systems.

DOI: 10.22448/AMJ.2016.15-16.95-96

UDC 617-089: 616-08-031.8

HYPERBARIC OXYGENATION AND ANTIOXIDANTS IN THE TREATMENT OF DEEP BURNS

Olifirova O.S., Kozka A.A., Volosenkova E.A.

\section{Amur State Medical Academy, Blagoveshchensk, Russia}

Topicality. Deep burns therapy is a great problem in combustiology and surgery. At present, a significance of the radicals reactions of lipid peroxidation (LPO) in molecular basis of the wound process is known [1]. Correction of LPO disorders in wound therapy is the basis of pathogenetic application of antioxidants and hyperbaric oxygenation (HBO). These are natural antioxidants, obtained out of the wood of Dahurian larch - dihydroquercetin (taxifolin) and arabinogalactan [2]. Besides, hyperbaric oxygenation stirs up phagocytic activity of reparation cells and rate of their entering the wound, stimulates antibacterial therapy action [3].

Objective: to assess the results of complex application of hyperbaric oxygenation and antioxidants (dihydroquercetin and arabinogalactan) in the treatment of patients with deep burns.

Materials and methods: the analysis of therapy results of 28 patients with burns of the III degree (ICD-10) was carried out. Among them there were 20 men $(71,4 \%)$ and 8 women $(28,6 \%)$ at the age of $24-66$. Ethiology of thermal burns: scalds - in 18 patients $(64,3 \%)$, flame burns - in 9 patients $(32,1 \%)$ and electric burn - in 1 case $(3,6 \%)$. Burn shock of the I-II degrees was marked in 2 patients with the burn area of $15 \%$ and $18 \%$. Duration of the course of the wound process was from 28 days till 3,2 months. On the average the area of thermal wounds $-530,8 \pm 11,7 \mathrm{~cm} 2$.

The main group (MG) included 14 patients receiving HBO and antioxidant therapy. Antioxidant therapy included oral intake of biologically active supplement containing flavonoids' formula of dihydroquercetin and arabinogalactan $(1: 3)$ in the dose of 1 capsule twice a day during 21 days from the beginning of therapy. Besides, after stopping burn shock and performing necrectomy the patients of the main group received 4 procedures of HBO in 1,5-1,8 atm during 40 minutes daily in pressure chamber "OKA-MT". Then postponed 